\title{
Özdeş İki Spektrofotometrenin Cihazlar Arası Güvenilirlik Ve Tekrarlanabilirliğinin İncelenmesi
}

\author{
Tuba Yılmaz Savaş(0000-0002-6516-276X) ${ }^{\alpha}$, Abdulhaluk Savaş(0000-0002-8897-3928) ${ }^{\beta}$, \\ Ali Rıza Tunçdemir(0000-0002-6114-3369) ${ }^{\beta}$
}

Selcuk Dent J, 2021; 8: 605-610 (Doi: 10.15311/selcukdentj.1009775)

Bašuru Tarihi: 14 Ekim 2021 Yayına Kabul Tarihi: 28 Ekim 2021

\section{ÖZ}

\section{Özdeş İki Spektrofotometrenin Cihazlar Arası Güvenilirlik} Ve Tekrarlanabilirliğinin İncelenmesi

Amaç: Bu in-vitro çalışmanın amacı, farklı yazııımlara sahip özdeş iki spektrofotometrenin tekrarlanabilirliğini ve cihazlar arası güvenilirliğini değerlendirmektir.

Gereç ve Yöntemler: Bir renk skalasına (Vita 3D-Master, Vita Zahnfabrik) ait 26 adet renk tabı, farklı yazıımlara sahip (v509i: A cihazı, v505p: B cihazı) iki özdeş spektrofotometre (Vita EasyShade V) ile ölçüldü ve CIELab değerleri kaydedildi $(n=260)$. Spektrofotometrelerin ölçümleri arasındaki renk farkları $\left(\Delta \mathrm{E}_{00}\right)$ hesaplandı. Tekrarlanabilirlik değerlendirilmesi için aynı skalanın 3M2 renk tabı, iki spektrofotometre ile ölçüldü $(n=50)$. Cihazların skala ile renk essleștirme doğruluk oranı hesaplandı. Cihazlar arası güvenilirlik ve cihazlar arasındaki ölçüm farkları, sınıf içi korelasyon katsayısı (ICC), Cronbach's alfa ve Paired T-testi kullanılarak hesaplandı $(\alpha=0.05)$.

Bulgular: Cihazlar arası güvenilirlik $L^{*}$, $a^{*}$ ve $b^{*}$ parametreleri için yüksek düzeyde bulunmuştur (ICC >0.99). Renk skalasının $\Delta \mathrm{E}_{00}$ değerleri 0.21 ile 1.78 arasında değişmektedir ve skaladaki bütün renklerin $\Delta \mathrm{E}_{00}$ değerleri kabul edilebilirlik eşik değerinin altındadır $\left(\Delta \mathrm{E}_{00}<1.8\right)$. A cihazının ortalama $L^{*}$ değeri $B$ cihazından önemli derecede yüksek $(P<0.001)$, ortalama $a^{*}$ ve $b^{*}$ değerleri ise önemli derecede düşük bulunmuştur $(P<0.001)$. Tekrarlanabilirlik her iki cihazda $a^{*}$ ve $b^{*}$ parametresi için mükemmel $(S D<0.1), L^{*}$ parametresi için ise biraz daha düşüktür $(0.15<S D<0.25)$. Her iki cihazın skala ile renk eşleştirme doğruluk oranı \% 34.6 olarak hesaplanmıştır.

Sonuç: İki özdeş spektrofotometrenin cihazlar arası güvenilirliği ve tekrarlanabilirliği yüksek; renk farkı değerleri ise kabul edilebilir düzeyde bulunmuştur. Ancak her iki cihaz, aynı renk skalası için farklı $L^{*}, a^{*}$ ve $b^{*}$ değeri ölçümü yapabilmektedir.

\section{ANAHTAR KELIMELER}

Cihaz hatası analizi, Güvenilirlik, Renk, Spektrofotometri, Tekrarlanabilirlik

Renk uyumu, dental restorasyonlarda iyi bir estetik sonuç elde etmek için gerekli olan temel faktörlerden biridir. ${ }^{1,2}$ Renk ölçümü genellikle görsel olarak renk skalaları ile yapıımaktadır. ${ }^{3}$ Doğal bir dişin renginin görsel olarak belirlenmesi, anatomik ve çevresel koşullara da bağlı olarak bireyler arasında değişiklik gösterebilir. Bu durum renk değerlendirmelerinde farlılıklara yol açar. ${ }^{4,5}$ Geçtiğimiz yıllarda diş renginin

\section{ABSTRACT}

Evaluation of Interdevice Reliability and Repeatability of Two Identical Spectrophotometers

Background: The purpose of this in-vitro study was to evaluate the repeatability and interdevice reliability of two identical spectrophotometers with different software.

Methods: Twenty-six shade tabs of a shade guide (Vita 3D-Master, Vita Zahnfabrik) were measured with two identical spectrophotometers (Vita EasyShade V) with different software (v509i: Device A; v505p: Device B), and CIELab values were recorded $(n=260)$. The color difference $\left(\Delta E_{00}\right)$ values between measurements of spectrophotometers were calculated. For repeatability, the 3M2 shade tab of the same shade guide was measured 50 times with each spectrophotometer. The matching accuracy rate of the devices with shade guide was calculated. Interdevice reliability and differences between devices were calculated using intraclass correlation coefficient (ICC), Cronbach's alpha, and Paired T-test $(\alpha=0.05)$.

Results: Interdevice reliability was found to be high for $\mathrm{L}^{*}, \mathrm{a}^{*}$, and $\mathrm{b}^{*}$ parameters (ICC>0.99). The $\Delta \mathrm{E}_{00}$ values of the shade tabs range from 0.21 to 1.78 , which were lower than the acceptability threshold $\left(\Delta \mathrm{E}_{00}<1.8\right)$. The mean $L^{*}$ value of Device $A$ was significantly higher than that of Device $B(P<0.001)$, while the mean $a^{*}$ and $b^{*}$ values were significantly lower $(P<0.001)$. The repeatability is excellent for $a^{*}$ and $b^{*}$ parameters $(S D<0.1)$, however, slightly lower for the $L^{*}(0.15<S D<0.25)$ in both devices. The matching accuracy rates of both devices were calculated as $34.6 \%$.

Conclusion: The reliability and repeatability of two identical spectrophotometers were found to be high, and the color difference values were found to be at an acceptable level. However, both devices can display different $L^{*}, a^{\star}$, and $b^{*}$ values for the same shade guide.

\section{KEYWORDS}

Color, Equipment failure analysis, Reliability, Repeatability, Spectrophotometry

dijital olarak belirlenmesi için elektronik cihazlar klinikte kullanıma sunulmuştur. Bu cihazlar ölçüm yöntemlerindeki farklara bağı olarak kolorimetre veya spektofotometre olarak adlandırılırlar. ${ }^{3}$ Dijital renk ölçümü, subjektif değişkenlerinden etkilenmediği için daha tutarlı sonuçlar ortaya koyabilir. ${ }^{6}$

\section{Uluslararası Standartlar Teşkilatı (International}

\footnotetext{
${ }^{\alpha}$ Selçuk Üniversitesi Diş Hekimliği Fakültesi Protetik Diş Tedavisi AD, Konya, Türkiye

${ }^{\beta}$ Necmettin Erbakan Üniversitesi Diş Hekimliği Fakültesi Protetik Diş Tedavisi AD, Konya, Türkiye
} 
Organization for Standardization - ISO) cihaz tekrarlanabilirliğini, renk parametreleri ölçümlerinin tutarlılığı veya tekrarlanan ölçümlerde renk skala sistemleriyle doğru eşleştirme olarak tanımlamıştır. Cihazlar arası güvenilirlik ise renk ölçümlerinde veya renk eşleştirmelerinde cihazlar arasındaki tutarlıı̆ın derecesi olarak tanımlanır. ${ }^{7}$ Önceki çalışmalar, spektrofotometrelerin güvenilirliğinin ve doğruluğunun kolorimetrelerden daha üstün olduğunu göstermiştir. ${ }^{3,6}$ Ancak, aynı materyalin farklı cihazlarla kaydedilen ölçümleri farklılık gösterebilir, bu nedenle "gerçek rengin" ölçülüp ölçülmediği belirsizdir. ${ }^{8}$ Yine de çalışmalar, spektrofotometrelerin görsel renk seçiminden daha güvenilir olduğunu göstermiştir. ${ }^{9}$

Renk ölçüm cihazları, düz bir yüzey yerine kavisli olan diş yüzeyini ölçer. Cihazın küçük ölçüm alanı, renk yorumunda sapmaya neden olabilecek bir kenar kaybı (edge-loss) etkisine neden olabilir. ${ }^{2}$ Örneklerin yarı saydam olması, cihazın tekrarlanabilirliğini ve doğruluğunu etkileyebilir. ${ }^{10}$ Ayrıca, ölçüm ucunun diş yüzeyine aynı şekilde konumlandırmak her zaman mümkün olamayabilir. ${ }^{11}$

VITA Easyshade V (VITA Zahnfabrik, Bad Säckingen, Almanya), taşınabilir bir spektrofotometre ve yeni bir beşinci nesil Easyshade'dir. Renk bilgilerini VITA 3DMaster sisteminde, VITA Classic sisteminde, VITABLOCS renklerinde veya diş beyazlatma renklerinde yorumlanmasına izin veren teknoloji geliştirilmiştir. ${ }^{1}$ Cihaz, V505p versiyonu ile piyasaya sürülmüş, daha sonra V507h ve V509i versiyonları ile güncellenmiştir.

Vita EasyShade Advance (4. Nesil EasyShade) ile Vita EasyShade V'in karşılaştıııldığı bir çalışmada cihazlar arası güvenilirlik ve tekrarlanabilirlik değerleri oldukça yüksek bulunmuş ve klinik olarak iki cihazın da güvenle kullanılabileceği bildirilmiştir. ${ }^{12}$ Aynı marka ve modelde farklı iki EasyShade V cihazının in-vitro ve in-vivo olarak karşılaştırıldığı (V505p ve V507h) başka bir çalışmada da cihazlar arası güvenilirlik ve doğruluk yüksek düzeyde bulunmuştur. Ancak aynı diş için farklı renk parametreleri elde edildiği bildirilmiştir. ${ }^{1}$ Bununla birlikte, aynı iki EasyShade V cihazının v505p ve v509i versiyonlarının güvenilirlik ve tekrarlanabilirliğinin değerlendirildiği bir çalışmaya literatürde rastlanılamamıştır.

Bu in-vitro çalışmanın amacı, farklı yazılımlara (V505p ve V509i) sahip özdeş iki spektrofotometrenin tekrarlanabilirliğinin, cihazlar arası güvenilirliğinin ve doğru renk eşleştirme oranlarının değerlendirilmesidir. $\mathrm{Bu}$ çalışmanın sıfır hipotezleri; aynı markaya ve farklı yazılıma sahip özdeş iki spektroforometrenin cihazlar arası güvenilirliği, tekrarlanabilirliği ve renk eşleştirme doğruluk oranları arasında bir fark olmayacağı, iki spektrofotometrenin ölçümlerinden elde edilen ortalama $L^{*}, a^{*}$ ve $b^{*}$ değerleri arasında bir fark olmayacağı ve aynı skalaya ait renk tablarının spektrofotometrelerin ölçümleri arasındaki renk farkı
$\left(\Delta \mathrm{E}_{00}\right)$ değerlerinin kabul edilebilirlik eşik değerinden fazla olmayacağıdır $\left(\Delta \mathrm{E}_{00}<1.8\right)$.

\section{GEREÇ VE YÖNTEMLER}

Bir renk skalasına (Vita 3D-Master, Vita Zahnfabrik, Bad Säckingen, Almanya) ait 26 adet renk tabı, farklı yazılımlara sahip (V509i: A cihazı, V505p: B cihazı) iki özdeş spektrofotometre (Vita EasyShade V, Vita Zahnfabrik) ile10'ar kez ölçüldü (Resim 1).

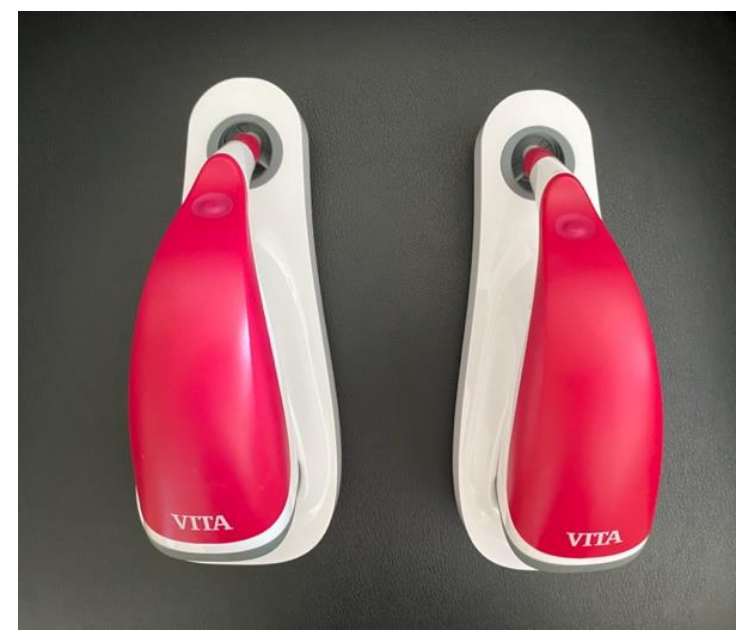

Resim 1

Çalışmada kullanılan iki farklı yazılıma sahip özdeş spektrofotometreler

Ölçümler nötral gri bir arka planda gerçekleştirildi (Digital Grey Card, Micnova, Çin). Cihazın ölçüm ucu, renk tablarının orta üçlüsünde konumlandıııldı. ${ }^{8}$ Bütün ölçümler aynı araştırmacı tarafından gerçekleştirildi. Her renk tabının ölçümünden önce, cihaz üretici talimatları doğrultusunda kalibre edildi. Renk skalasının $L^{*}, a^{*}, b^{*}$ değerleri kaydedildi ( $n=260)$.

Skaladaki her bir rengin $A$ ve $B$ cihazı ile ölçümleri arasındaki renk farkları CIEDE2000 formülü $\left(\Delta \mathrm{E}_{00}\right)$ hesapland.. ${ }^{13}$

$\Delta E_{00}=\left[\left(\frac{\Delta L^{\prime}}{K_{L} S_{L}}\right)^{2}+\left(\frac{\Delta C^{\prime}}{K_{C} S_{C}}\right)^{2}+\left(\frac{\Delta H^{\prime}}{K_{H} S_{H}}\right)^{2}+R_{T}\left(\frac{\Delta C^{\prime}}{K_{C} S_{C}}\right)\left(\frac{\Delta H^{\prime}}{K_{H} S_{H}}\right)\right]^{1 / 2}$

Formulasyondaki $\Delta L^{\prime}, \Delta C^{\prime}$ ve $\Delta H^{\prime}$ birbirinden faklı 2 ölçüm arasındaki parlaklık (lightness), renk yoğunluğu (chroma) ve renk tonu (hue) farklarını tanımlar. $S_{L}, S_{C}$ ve $S_{H}$ renk yoğunluğu ve renk tonuna ait ağırlık fonksiyonlarını ifade eder. $R_{T}$; $C I E ~ L * a * b$ renk sistemindeki mavi alandaki renk yoğunluğu ve renk tonu farklılıkları arasındaki etkileşim miktarını tanımlayan devir fonksiyonudur. $\mathrm{K}_{\mathrm{L}}, \mathrm{K}_{\mathrm{C}}$ ve $\mathrm{K}_{\mathrm{H}}$ parlaklık, renk yoğunluğu ve renk tonu için değerlendirilen parametrik faktörlerdir. Bu çalışmada $K_{L}, K_{C}$ ve $K_{H}$ "1" olarak kabul edildi.

Paravina ve ark. ${ }^{14}$ tarafından yapılan çalışmada CIEDE2000 \% 50 algılanabilirlik eşiği $\Delta \mathrm{E}_{00}=0.8$ birim ve $\% 50$ kabul edilebilirlik eşiği $\Delta \mathrm{E}_{00}=1.8$ birim olarak rapor edilmiştir. Bu değerler mevcut çalışmada eşik değerler olarak kullanılmıştır. 
Tekrarlanabilirlik değerlendirilmesi için aynı skalanın 3M2 renk tabı, özdeş iki spektrofotometre ile aynı araştırmacı tarafından 50 kez ölçüldü $(n=50)$. Ölçümlerden elde edilen $L^{*}, a^{*}$ ve $b^{*}$ parametrelerinin standart sapma değerleri tekrarlanabilirlik değerlendirmesi için kullanıldı. ${ }^{12}$

Bu çalışmada, cihazların eşleştirme performansını analiz etmek için VITA 3D-Master (Vita Zahnfabrik) renk skala sistemi kullanıldı. Cihazın renk skala sistemine uyum derecesi cihaz ekranında yeşil (iyi), sarı (ortalama) veya kırmızı çubukla (ayarla) belirtilmektedir. Bu çalışmada sadece "iyi" eşleştirme sonuçları kullanılmıştır. ${ }^{1}$ Her bir cihaz için, renk skalasındaki 26 rengin 260 adet ölçümündeki yeşil "(iyi)" adeti toplam ölçüme oranlanarak cihazların skala ile renk eşleştirme doğruluk oranı hesaplanmıştır.

İstatistiksel analizler bir bilgisayar programı (SPSS 26, IBM Corp., Amerika) ile gerçekleştirildi. Cihazlar arası güvenilirlik için, sınıf içi korelasyon katsayısı (ICC) ve Cronbach's alfa analizleri kullanıldı. Sınıf içi korelasyon katsayısı hesaplaması, iki yönlü karma etki modeli, mutlak uyum ve ortalama ölçüm modeli ile elde edildi $(\alpha=0.05)$. Cihazlar arasındaki ölçüm farkları ise Paired Ttesti kullanılarak hesaplandı $(\alpha=0.05)$.

\section{BULGULAR}

$\mathrm{Bu}$ çalışmada iki spektrofotometre ile cihazlar arası güvenilirlik ve renk farkı hesaplamaları için 520 adet, tekrarlanabilirlik değerlendirmesi için 100 adet, toplam 620 adet renk ölçümü yapıldı. Renk skalasının A ve B cihazlarıyla ölçümünden elde edilen ortalama $L^{*}, a^{*}, b^{*}$ değerleri ve $\Delta \mathrm{E}_{00}$ değerleri Tablo 1'deki gösterilmiştir.

Renk skalasının $\Delta \mathrm{E}_{00}$ değerleri 0.21 ile 1.78 arasında değişmektedir ve skaladaki bütün renklerin $\Delta \mathrm{E}_{00}$ değerleri kabul edilebilirlik eşik değerinin altındadır $\left(\Delta \mathrm{E}_{00}<1.8\right)$. A cihazının ortalama $L^{*}$ değeri $B$ cihazından önemli derecede yüksek $(P<0.001)$ bulunmuştur. $A$ cihazının ortalama $a^{*}$ ve $b^{*}$ değerleri ise $B$ cihazından önemli derecede düşük bulunmuştur $(P<0.001)$ (Tablo 2).

Cihazlar arası güvenilirlik $L^{*}$, $a^{*}$ ve $b^{*}$ parametreleri için yüksek düzeyde bulunmuştur (ICC>0.99) (Tablo 3). Tekrarlanabilirlik; her iki cihazda $a^{*}$ ve $b^{*}$ parametresi için mükemmel $(S D<0.1), L^{*}$ parametresi için ise biraz daha düşük $(0.15<S D<0.25)$ bulunmuştur (Tablo 4). Her iki cihazın skala ile renk eşleştirme doğruluk oranı \% 34.6 olarak hesaplanmıştır.
Tablo 1.

Renk skalasında yer alan 26 adet renk tabının $A$ ve $B$ cihazı ile elde edilen $L^{*}, a^{*}, b^{*}$ ve $\Delta E_{00}$ parametrelerinin ortalama ve standart sapma değerleri $(n=10)$

\begin{tabular}{|c|c|c|c|c|c|c|c|}
\hline & & A CIHAZI & & & B CIHAZI & & \\
\hline & $L^{*}$ & $a^{*}$ & $b^{*}$ & $L^{*}$ & $a^{*}$ & $b^{*}$ & $\Delta \mathrm{E}_{00}$ \\
\hline $1 \mathrm{M} 1$ & $\begin{array}{l}83.86 \\
(0.49)\end{array}$ & $\begin{array}{l}-0.79 \\
(0.32)\end{array}$ & $\begin{array}{l}11.93 \\
(0.13)\end{array}$ & $\begin{array}{l}83.18 \\
(0.13)\end{array}$ & $\begin{array}{c}-0.64 \\
(0.05)\end{array}$ & $\begin{array}{l}12.55 \\
(0.12)\end{array}$ & $\begin{array}{c}0.71 \\
(0.15)\end{array}$ \\
\hline $1 \mathrm{M} 2$ & $\begin{array}{l}83.50 \\
(0.20)\end{array}$ & $\begin{array}{c}0.12 \\
(0.04)\end{array}$ & $\begin{array}{l}16.61 \\
(0.07)\end{array}$ & $\begin{array}{l}82.96 \\
(0.14)\end{array}$ & $\begin{array}{c}0.44 \\
(0.05)\end{array}$ & $\begin{array}{l}17.31 \\
(0.09)\end{array}$ & $\begin{array}{c}0.71 \\
(0.07)\end{array}$ \\
\hline $2 \mathrm{M} 1$ & $\begin{array}{l}79.22 \\
(0.16)\end{array}$ & $-0.10(0)$ & $\begin{array}{l}12.87 \\
(0.04)\end{array}$ & $\begin{array}{l}78.07 \\
(0.18)\end{array}$ & $\begin{array}{c}0.11 \\
(0.03)\end{array}$ & $\begin{array}{l}13.45 \\
(0.08)\end{array}$ & $\begin{array}{c}0.94 \\
(0.12)\end{array}$ \\
\hline 2M2 & $\begin{array}{l}77.42 \\
(0.12)\end{array}$ & $\begin{array}{c}1.34 \\
(0.06)\end{array}$ & $\begin{array}{l}17.55 \\
(0.15)\end{array}$ & $\begin{array}{l}76.61 \\
(0.18)\end{array}$ & $\begin{array}{c}1.59 \\
(0.07)\end{array}$ & $\begin{array}{l}17.88 \\
(0.18)\end{array}$ & $\begin{array}{c}0.69 \\
(0.20)\end{array}$ \\
\hline $2 \mathrm{M} 3$ & $\begin{array}{l}78.53 \\
(0.10)\end{array}$ & $0.60(0)$ & $\begin{array}{l}23.47 \\
(0.15)\end{array}$ & $\begin{array}{l}77.54 \\
(0.09)\end{array}$ & $0.80(0)$ & $\begin{array}{l}24.07 \\
(0.22)\end{array}$ & $\begin{array}{c}0.79 \\
(0.11)\end{array}$ \\
\hline 2L1.5 & $\begin{array}{l}77.60 \\
(0.16)\end{array}$ & $0(0)$ & $\begin{array}{c}14.58( \\
0.14)\end{array}$ & $\begin{array}{l}76.45 \\
(0.15) \\
\end{array}$ & $\begin{array}{c}0.27 \\
(0.04)\end{array}$ & $\begin{array}{l}15.11 \\
(0.15)\end{array}$ & $\begin{array}{c}0.95 \\
(0.08)\end{array}$ \\
\hline 2L2.5 & $\begin{array}{l}80.16 \\
(0.09)\end{array}$ & $\begin{array}{c}0.66 \\
(0.05)\end{array}$ & $\begin{array}{l}26.08 \\
(0.10)\end{array}$ & $\begin{array}{l}78.89 \\
(0.18)\end{array}$ & $0.90(0)$ & $\begin{array}{l}26.54 \\
(0.14)\end{array}$ & $\begin{array}{c}0.94 \\
(0.11)\end{array}$ \\
\hline 2R1.5 & $\begin{array}{l}78.34 \\
(0.18)\end{array}$ & $\begin{array}{l}0.64( \\
0.06)\end{array}$ & $\begin{array}{l}13.95 \\
(0.08) \\
\end{array}$ & $\begin{array}{l}77.00 \\
(0.18) \\
\end{array}$ & $\begin{array}{c}0.86 \\
(0.05)\end{array}$ & $\begin{array}{l}14.54 \\
(0.12) \\
\end{array}$ & $\begin{array}{c}1.07 \\
(0.12)\end{array}$ \\
\hline 2R2.5 & $\begin{array}{l}78.17 \\
(0.15)\end{array}$ & $\begin{array}{c}2.12 \\
(0.06)\end{array}$ & $\begin{array}{l}19.74 \\
(0.09)\end{array}$ & $\begin{array}{l}77.76 \\
(0.32)\end{array}$ & $\begin{array}{c}1.53 \\
(0.34)\end{array}$ & $\begin{array}{l}22.66 \\
(0.90)\end{array}$ & $\begin{array}{c}1.78 \\
(0.33)\end{array}$ \\
\hline 3M1 & $\begin{array}{l}74.64 \\
(0.22)\end{array}$ & $\begin{array}{c}1.1 \\
(0.04)\end{array}$ & $\begin{array}{l}14.30 \\
(0.06) \\
\end{array}$ & $\begin{array}{l}73.91 \\
(0.22) \\
\end{array}$ & $\begin{array}{c}1.38 \\
(0.42)\end{array}$ & $\begin{array}{l}15.10 \\
(0.06)\end{array}$ & $\begin{array}{c}0.80 \\
(0.19)\end{array}$ \\
\hline $3 \mathrm{M} 2$ & $\begin{array}{l}75.64 \\
(0.14)\end{array}$ & $1.7(0)$ & $\begin{array}{l}23.15 \\
(0.08)\end{array}$ & $\begin{array}{l}74.66 \\
(0.14)\end{array}$ & $1.9(0)$ & $\begin{array}{l}23.66 \\
(0.11)\end{array}$ & $\begin{array}{c}0.79 \\
(0.14)\end{array}$ \\
\hline $3 \mathrm{M} 3$ & $\begin{array}{l}75.65 \\
(0.16)\end{array}$ & $1.3(0)$ & $\begin{array}{l}26.89 \\
(0.16) \\
\end{array}$ & $\begin{array}{l}74.36 \\
(0.09) \\
\end{array}$ & $\begin{array}{c}1.59 \\
(0.03)\end{array}$ & $\begin{array}{l}27.77 \\
(0.13)\end{array}$ & $\begin{array}{c}1.05 \\
(0.09)\end{array}$ \\
\hline 3L1.5 & $\begin{array}{l}72.68 \\
(0.18)\end{array}$ & $\begin{array}{c}2.02 \\
(0.04)\end{array}$ & $\begin{array}{l}18.22 \\
(0.07)\end{array}$ & $\begin{array}{l}72.58 \\
(0.12)\end{array}$ & $\begin{array}{c}2.00 \\
(0.00)\end{array}$ & $\begin{array}{c}18.0 \\
(0.06)\end{array}$ & $\begin{array}{c}0.18 \\
(0.09)\end{array}$ \\
\hline 3L2.5 & $\begin{array}{l}73.71 \\
(0.27)\end{array}$ & $\begin{array}{l}1.20 \\
(0.0)\end{array}$ & $\begin{array}{l}23.35 \\
(0.17)\end{array}$ & $\begin{array}{l}73.95 \\
(0.18)\end{array}$ & $\begin{array}{c}1.25 \\
(0.05)\end{array}$ & $\begin{array}{l}25.59 \\
(0.17)\end{array}$ & $\begin{array}{c}0.28 \\
(0.18)\end{array}$ \\
\hline 3R1.5 & $\begin{array}{l}72.00 \\
(0.15)\end{array}$ & $\begin{array}{c}1.39 \\
(0.05)\end{array}$ & $\begin{array}{l}13.79 \\
(0.12)\end{array}$ & $\begin{array}{l}72.20 \\
(0.11)\end{array}$ & $\begin{array}{c}1.35 \\
(0.05)\end{array}$ & $\begin{array}{l}13.87 \\
(0.08)\end{array}$ & $\begin{array}{c}0.21 \\
(0.09)\end{array}$ \\
\hline $3 R 2.5$ & $\begin{array}{l}74.77 \\
(0.09)\end{array}$ & $\begin{array}{c}2.28 \\
(0.04)\end{array}$ & $\begin{array}{l}26.42 \\
(0.21)\end{array}$ & $\begin{array}{l}74.41 \\
(0.13)\end{array}$ & $\begin{array}{c}2.25 \\
(0.05)\end{array}$ & $\begin{array}{l}26.17 \\
(0.11)\end{array}$ & $\begin{array}{c}0.34 \\
(0.11)\end{array}$ \\
\hline $4 \mathrm{M} 1$ & $\begin{array}{l}67.95 \\
(0.13)\end{array}$ & $\begin{array}{c}1.94 \\
(0.05)\end{array}$ & $\begin{array}{l}14.08 \\
(0.10)\end{array}$ & $\begin{array}{l}66.69 \\
(0.09) \\
\end{array}$ & $\begin{array}{c}2.19 \\
(0.03)\end{array}$ & $\begin{array}{l}14.72 \\
(0.07)\end{array}$ & $\begin{array}{c}1.27 \\
(0.10)\end{array}$ \\
\hline $4 \mathrm{M} 2$ & $\begin{array}{l}69.80 \\
(0.38)\end{array}$ & $\begin{array}{c}2.49 \\
(0.03)\end{array}$ & $\begin{array}{l}23.87 \\
(0.10)\end{array}$ & $\begin{array}{l}68.89 \\
(0.12)\end{array}$ & $\begin{array}{c}2.65 \\
(0.05)\end{array}$ & $\begin{array}{l}24.27 \\
(0.09)\end{array}$ & $\begin{array}{c}0.78 \\
(0.22)\end{array}$ \\
\hline $4 \mathrm{M} 3$ & $\begin{array}{l}69.75 \\
(0.18)\end{array}$ & $\begin{array}{c}2.25 \\
(0.05)\end{array}$ & $\begin{array}{l}30.04 \\
(0.14)\end{array}$ & $\begin{array}{l}68.49 \\
(0.15)\end{array}$ & $\begin{array}{c}2.58 \\
(0.06)\end{array}$ & $\begin{array}{l}30.51 \\
(0.16)\end{array}$ & $\begin{array}{c}1.05 \\
(0.19)\end{array}$ \\
\hline 4L1.5 & $\begin{array}{l}68.81 \\
(0.12)\end{array}$ & $\begin{array}{c}3.05 \\
(0.05)\end{array}$ & $\begin{array}{l}18.95 \\
(0.07)\end{array}$ & $\begin{array}{l}68.64 \\
(0.12)\end{array}$ & $\begin{array}{c}3.01 \\
(0.05)\end{array}$ & $\begin{array}{l}18.66 \\
(0.16)\end{array}$ & $\begin{array}{c}0.24 \\
(0.10)\end{array}$ \\
\hline 4L2.5 & $\begin{array}{l}68.71 \\
(0.18)\end{array}$ & $\begin{array}{c}2.1 \\
(0.04)\end{array}$ & $\begin{array}{l}28.29 \\
(0.21)\end{array}$ & $\begin{array}{l}68.71 \\
(0.17)\end{array}$ & $\begin{array}{c}2.18 \\
(0.04)\end{array}$ & $\begin{array}{l}28.39 \\
(0.15)\end{array}$ & $\begin{array}{c}0.18 \\
(0.07)\end{array}$ \\
\hline 4R1.5 & $\begin{array}{l}68.36 \\
(0.11)\end{array}$ & $\begin{array}{c}3.65 \\
(0.07)\end{array}$ & $\begin{array}{l}17.50 \\
(0.09)\end{array}$ & $\begin{array}{l}68.40 \\
(0.13)\end{array}$ & $\begin{array}{c}3.66 \\
(0.05)\end{array}$ & $\begin{array}{l}17.37 \\
(0.06)\end{array}$ & $\begin{array}{c}0.18 \\
(0.07)\end{array}$ \\
\hline 4R2.5 & $\begin{array}{l}69.85 \\
(0.17)\end{array}$ & $\begin{array}{c}2.78 \\
(0.06)\end{array}$ & $\begin{array}{l}26.74 \\
(0.23)\end{array}$ & $\begin{array}{l}69.58 \\
(0.09)\end{array}$ & $\begin{array}{c}2.87 \\
(0.04)\end{array}$ & $\begin{array}{l}26.61 \\
(0.16)\end{array}$ & $\begin{array}{c}0.27 \\
(0.12)\end{array}$ \\
\hline $5 \mathrm{M} 1$ & $\begin{array}{l}62.59 \\
(0.23)\end{array}$ & $\begin{array}{c}4.49 \\
(0.05)\end{array}$ & $\begin{array}{l}17.86 \\
(0.08)\end{array}$ & $\begin{array}{l}61.43 \\
(0.12)\end{array}$ & $\begin{array}{c}4.72 \\
(0.04)\end{array}$ & $\begin{array}{l}18.12 \\
(0.04)\end{array}$ & $\begin{array}{c}1.03 \\
(0.26)\end{array}$ \\
\hline $5 \mathrm{M} 2$ & $\begin{array}{l}65.92 \\
(0.09)\end{array}$ & $3.5(0)$ & $\begin{array}{l}27.49 \\
(0.09)\end{array}$ & $\begin{array}{l}64.50 \\
(0.08)\end{array}$ & $\begin{array}{c}3.71 \\
(0.03)\end{array}$ & $\begin{array}{l}27.77 \\
(0.06)\end{array}$ & $\begin{array}{c}1.19 \\
(0.08)\end{array}$ \\
\hline $5 \mathrm{M} 3$ & $\begin{array}{l}65.45 \\
(0.08)\end{array}$ & $\begin{array}{c}4.07 \\
(0.06)\end{array}$ & $\begin{array}{l}34.56 \\
(0.19)\end{array}$ & $\begin{array}{l}64.24 \\
(0.09)\end{array}$ & $\begin{array}{c}4.35 \\
(0.05)\end{array}$ & $\begin{array}{l}34.66 \\
(0.17)\end{array}$ & $\begin{array}{c}1.02 \\
(0.13)\end{array}$ \\
\hline
\end{tabular}

Tablo 2.

A ve $B$ Cihazı ölçümü ile elde edilen ortalama $L^{*}, a^{*}$ ve $b^{*}$ değerleri $(n=260)$

\begin{tabular}{|cccc|} 
& $\begin{array}{c}\text { A Cihazı, Ortalama } \\
\text { (SS) }\end{array}$ & $\begin{array}{c}\text { B Cihazı, Ortalama } \\
\text { (SS) }\end{array}$ & P Değeri \\
\hline $\mathrm{L}^{*}$ & $73.58(5.52)$ & $72.85(5.51)$ & $<0.001$ \\
\hline $\mathrm{a}^{*}$ & $1.76(1.30)$ & $1.90(1.28)$ & $<0.001$ \\
\hline $\mathrm{b}^{*}$ & $20.93(6.12)$ & $21.35(6.05)$ & $<0.001$ \\
\hline
\end{tabular}

SS: Standart Sapma 
Tablo 3.

\section{Cihazlar arası güvenilirlik için sınıf içi korelasyon katsayısı (ICC) değerleri}

\begin{tabular}{|cccc|}
\hline & Cronbach's Alfa & ICC & P Değeri \\
\hline$L^{*}$ & 0.997 & 0.993 & $<0.001$ \\
\hline $\mathrm{a}^{*}$ & 0.994 & 0.991 & $<0.001$ \\
\hline $\mathrm{b}^{*}$ & 0.997 & 0.996 & $<0.001$ \\
\hline
\end{tabular}

Tablo 4.

Tek renk tabı (3M2) için $A$ ve $B$ cihazlarının tekrarlanabilirliği $(n=50)$

\begin{tabular}{|ccc|}
\hline & A Cihazı & B Cinazı \\
\hline$L^{*}$ & 0.22 & 0.17 \\
\hline$a^{*}$ & 0.0 & 0.0 \\
\hline$b^{*}$ & 0.07 & 0.12 \\
\hline
\end{tabular}

\section{TARTIŞMA}

Bu in-vitro çalışmanın sonuçlarına göre, cihazlar arası güvenilirlik ve tekrarlanabilirlik çok yüksek bulunmuştur (ICC>0.99). Renk skalasına ait her bir renk tabının $A$ ve $B$ cihazı ölçümleri arasındaki renk farkları kabul edilebilirlik eşik değerinin altında bulunmuştur. Cihazların renk eşleştirme doğruluk oranları ise aynıdır. Ancak iki spektrofotometrenin ölçümlerinden elde edilen ortalama $L^{*}, a^{*}$ ve $b^{*}$ değerleri arasındaki fark önemli bulunmuştur $(P>0.05)$. Dolayısıyla sıfır hipotezi önemli bulunmuştur $(P>0.05)$. Dolayısıyla sıfır hipotezi kısmi olarak reddedilmiştir.

Önceki bir çalışma, VITA 3D-Master renk skala sisteminin, VITA Classic skala sistemden daha yeterli doğal diş renk aralığı içerdiğini rapor etmiştir. ${ }^{15}$ VITA 3D-Master sistemi kullanılarak üretilen seramik restorasyonların, doğal diş ile VITA Classic skala sistemi kullanılarak üretilenden daha az renk farkı ortaya koyduğunu bildirmiştir. ${ }^{16}$ Ayrıca spektrofotometrelerin güvenilirlik ve tekrarlanabilirliğini inceleyen birçok çalışma bu skala sistemini kullanmıştır. 1,8,12,17,18 $\mathrm{Bu}$ çalışmadan elde edilen verilerin literatür ile karşılaştırılabilmesi ve daha güvenilir sonuçlar ortaya koyması sebebi ile bu çalışmada 3D-Master renk skala sistemi tercih edilmiştir.

Sınıf içi korelasyon katsayısı 0.91 ile 0.99 arasında ise cihazlar arası çok yüksek (kusursuz - excellent) uyum olduğu belirtilmektedir. ${ }^{19}$ Sekiz adet Vita Easyhade Advance (4. Nesil EasyShade) modelinin kıyaslandığı bir çalışmada, $L^{*}, a^{*}$ ve $b^{*}$ parametreleri için cihazlar arası güvenilirlik çok yüksek bulunmuştur (ICC>0.9). ${ }^{17}$ Vita EasyShade Advance ile EasyShade V modellerinin güvenilirliğinin araştırıldığı başka bir çalışmada da $L^{*}$, $a *$ ve $b$ * parametreleri için ICC değeri 0.834 ile 0.995 arasında rapor edilmiştir. ${ }^{12}$ Farklı yazılımda (V505p ve V507h) iki adet Vita EasyShade
V'in karşılaştırıldığı başka bir çalışmada ise $L^{*}$, $a *$ ve $b$ * parametreleri için cihazlar arası ICC değerleri 0.897 ile 0.994 arasındadır.1 Bu çalışmadan elde edilen sınıf içi korelasyon katsayısı (ICC) değerleri 0.991 ile 0.996 arasında olup önceki çalışmalar ile uyumludur.

Klotz ve ark.12, Vita EasyShade Advance ile Vita EasyShade V'in tekrarlanabilirliğini maksimum deviasyon değerlerini hesaplayarak ölçmüş ve $L^{*}, a^{*}$, $b^{*}$ değerlerinin tekrarlanabilirliğini çok yüksek $(\leq 0.1)$ olarak rapor etmiştir. Bu çalışmada tekrarlanabilirlik her iki cihazda $a^{*}$ ve $b^{*}$ parametresi için mükemmel $(S D<0.1), L^{*}$ parametresi için ise biraz daha düşük $(0.15<\mathrm{SD}<0.25)$ bulunmuştur. Bunun nedeni cihazların farklı yazılımlara sahip olması olabilir.

Bu çalışmada iki cihazdan elde edilen ortalama $L^{*}$, $a^{*}$ ve $b^{\star}$ değerleri arasında istatistiksel olarak önemli fark bulunmuştur. Benzer olarak, önceki çalışmalarda da farklı spektrofotometreler ile yapılan renk ölçümlerinden aynı diş veya örnekler için farklı $L^{*}$, $a^{*}$ ve $b^{*}$ değerleri elde edildiği rapor edilmiştir. ${ }^{1,20}$

3D-Master renk skalasının cihazlar arası renk farkının CIEDE2000 formülü ile hesaplandığı bir çalışmada $\Delta \mathrm{E}_{00}$ değeri $2.26 \pm 0.43$ olarak bildirilmiştir. ${ }^{1}$ Weyhrauch ve ark. ${ }^{17}$, Vita 3D-Master skala sistemi renklerinde (29 renk, beyazlatma renk tabları da dahil) feldspatik porselenden (Vita VM9, Vita Zahnfabrik) ürettikleri seramik disklerin renklerini sekiz adet aynı spektrofotomotre (EasyShade Advance 4.0) ile ölçerek cihazlar arasındaki renk farkı $\left(\Delta \mathrm{E}_{\mathrm{ab}}\right)$ değerlerini her bir renk için hesaplamışlardır. Yazarlar ortalama $\Delta \mathrm{E}_{\mathrm{ab}}$ değerlerini 0.62 ile 1.67 birim arasında olarak rapor etmişlerdir. Bu çalışmada 3D-Master skalasındaki 26 adet renk tabının farklı iki spektrofotometrenin ölçümleri arasındaki renk farkı değerleri CIEDE2000 formülü ile hesaplanmıştır. Buna göre $\Delta E_{00}$ değerleri 0.24 ile 1.78 olarak bulunmuş ve kabul edilebilirlik eşiğinin altında olmuştur $\left(\Delta \mathrm{E}_{00}<1.8\right)$. Bu sonuç, farklı yazılımdaki özdeş iki spektrofotometreden farklı $L^{*}, a^{*}$ ve $b^{*}$ değerleri elde edilmiş olsa da ortaya çıkan renk farkının gözle ayırt edilebilecek bir renk farkı olmadığını ortaya koymaktadır.

Farklı yazılımlı (V507h ve V505p) iki EasyShade V'in kıyaslandığı yeni bir çalışmada doğru renk eşleştirme oranı V507h için \% 20.94, V505p için ise \% 12.82 olarak rapor edilmiştir. ${ }^{1}$ EasyShade, Shadepilot ve ShadeEye NCC cihazlarının karşılaştırıldığı başka bir çalışmada doğru renk eşleştirme oranları \% 37.7 ile \% 48.2 olarak rapor edilmiştir. ${ }^{21}$ Hugo ve ark.'nın ${ }^{22}$ yaptığı bir çalışmada da dijital renk ölçüm cihazlarının düşük eşleştirme oranları gösterdiği belirtilmiştir. Bu çalışmada cihazların renk skalası ile cihazın ekranında belirtilen renk ile eşleşme oranı her iki cihazda da \% 34.6'dır. Kullanılan her iki cihaz, Vita 3-D Master skalası ile renk eşleştirme işlemi sırasında 2 komşu renk arasında bir ara renk tonunu (ara rengi elde etmek için 2 rengin karışımı) göstermektedir. ${ }^{23} \mathrm{Bu}$ da renk skalası ile elde edilen düşük eşleştirme oranlarının nedeni 
olabilir. Ayrıca renk skalalarının üretim tarihleri ile kullanılan spektrofotometrelerin üretim tarihleri farklı olabileceğinden çalışılan cihazların algoritmalarının bu kılavuzun özelliklerine daha iyi uyumlanması gerekebilir. ${ }^{18}$ Ek olarak, aynı üreticiye ait renk skalaları arasında bile farklar olabileceği ve skalalar arasındaki üretim değişkenliğinin doğru olmayan renk ölçümlerine neden olabileceği de bildirilmiştir. ${ }^{8}$

Dijital renk ölçüm cihazları yüksek tekrarlanabilirlik sunmasına rağmen, bazı cihazlar, renk koordinat değerlerinde spektrofotometrik referans sisteminden önemli sapmalar gösterebilmektedir. ${ }^{20}$ Bu çalışmada da özdeş iki cihaz yüksek güvenilirlik ve tekrarlanabilirlik sunmasına rağmen, aynı skalanın renk ölçümlerinde farklı $L^{*}$, $a^{*}$ ve $b^{*}$ değerleri ölçmüşlerdir. Dolayısı ile üreticiler, dijital renk ölçüm sistemlerinin sonuçlarını karşılaştırılabilir hale getirmek için CIE renk ölçüm sistemine uygunluk açısından renk ölçüm cihazlarının doğruluğunu geliştirmelidir. ${ }^{24} \mathrm{Bu}$ çalışmada kullanılan renk skalasından farklı olarak, doğal dişler, renk ölçümünü etkileyebilecek değişken yüzey dokusuna ve anatomik varyasyonlara sahiptir. Minenin dentin üzerindeki katman etkisi ve doğal dişlerin değişen derecelerdeki yarı saydamlığı renk ölçümlerini zorlaştırabilir. ${ }^{8} \mathrm{Bu}$ çalışmanın in-vitro koşullarda yapılmış olması ve ölçümlerin sadece bir kişi tarafından gerçekleştirilmiş olması limitasyonlarıdır. $\mathrm{Bu}$ nedenle, kullanılan cihazların klinik koşullarda güvenilirlik ve tekrarlanabilirliğinin değerlendirildiği invivo çalışmalara intiyaç vardır.

\section{SONUÇ}

$\mathrm{Bu}$ çalışmanın limitasyonları dahilinde aşağıdaki sonuçlar çıkarılabilir:

1. İki özdeş spektrofotometrenin cihazlar arası güvenilirliği ve tekrarlanabilirliği çok yüksek bulunmuştur (ICC>0.99).

2. Aynı skalaya ait farklı iki spektrofotometreye ait ölçümler arasındaki renk farkı değerleri ise kabul edilebilir düzeyde bulunmuştur $\left(\Delta \mathrm{E}_{00}<1.8\right)$. Ancak her iki cihaz, aynı renk skalası için farklı $L^{*}, a^{*}$ ve $b^{*}$ değeri ölçümü yapabilmektedir.

3. Her iki cihaz da güvenilir ve tekrarlanabilir sonuçlar ürettiği için diş renginin klinik olarak belirlenmesinde kullanılabilir. Ayrıca bu çalışmanın sonucu, farklı iki yazılıma sahip yeni nesil spektrofotometrelerin performanslarının tahmini için klinisyenlere yardımcı olabilir. 


\section{KAYNAKLAR}

1. Kim HK. Evaluation of the repeatability and matching accuracy between two identical intraoral spectrophotometers: an in vivo and in vitro study. J Adv Prosthodont 2018;10:252-8.

2. Van der Burgt T, Ten Bosch J, Borsboom P, Kortsmit W. A comparison of new and conventional methods for quantification of tooth color. $J$ Prosthet Dent 1990;63:155-62.

3. Chu SJ, Trushkowsky RD, Paravina RD. Dental color matching instruments and systems. Review of clinical and research aspects. J Dent 2010;38 2-16.

4. Brewer JD, Wee A, Seghi R. Advances in color matching. Dent Clin North Am 2004;48:341-58.

5. Dagg H, O'connell B, Claffey N, Byrne D, Gorman C. The influence of some different factors on the accuracy of shade selection. J Oral Rehabil 2004;31:900-4.

6. Paul SJ, Peter A, Rodoni L, Pietrobon N. Conventional visual vs spectrophotometric shade taking for porcelainfused-to-metal crowns: a clinical comparison. J Prosthet Dent 2004;92:577.

7. International Organization for Standardization. ISO 57251. Accuracy (trueness and precision) of measurement methods and results - Part 1: General principles and definitions. Geneva: ISO; 1994. Available at: https://www.iso.org/obp/ ui/\#iso:std:iso:5725:-1:ed1:v1:en

8. Kim-Pusateri S, Brewer JD, Davis EL, Wee AG. Reliability and accuracy of four dental shade-matching devices. $J$ Prosthet Dent 2009;101:193-9.

9. Hammad IA. Intrarater repeatability of shade selections with two shade guides. J Prosthet Dent 2003;89:50-3.

10. Karaagaclioglu L, Terzioglu H, Yilmaz B, Yurdukoru B. In vivo and in vitro assessment of an intraoral dental colorimeter. J Prosthodont 2010;19:279-85.

11.Tsiliagkou A, Diamantopoulou S, Papazoglou E, Kakaboura A. Evaluation of reliability and validity of three dental colour-matching devices. Int $\mathrm{J}$ Esthet Dent 2016;11(1):2-16.

12. Klotz AL, Habibi Y, Corcodel N, Rammelsberg P, Hassel AJ, Zenthofer A. Laboratory and clinical reliability of two spectrophotometers. J Esthet Restor Dent. 2018:1-5.

13. Luo MR, Cui G, Rigg B. The development of the CIE 2000 colour-difference formula: CIEDE2000. Col Res Appl 2001;26:340-50.

14.Paravina RD, Ghinea R, Herrera LJ, Bona AD, Igiel C, Linninger $\mathrm{M}$ et al. Color difference thresholds in dentistry. J Esthet Restor Dent 2015;27 Suppl 1:S1-9.

15. Yuan JC-C, Brewer JD, Monaco Jr EA, Davis EL. Defining a natural tooth color space based on a 3-dimensional shade system. J Prosthet Dent 2007;98:110-9.

16. Öngül D, Şermet B, Balkaya MC. Visual and instrumental evaluation of color match ability of 2 shade guides on a ceramic system. J Prosthet Dent 2012;108:9-14.

17. Weyhrauch $M$, Igiel $C$, Pabst $A$, Wentaschek S, Scheller $\mathrm{H}$, Lehmann $\mathrm{K}$. Interdevice agreement of eight equivalent dental color measurement devices. Clin Oral Investig 2015;19:2309-18.
18. Llena C, Lozano E, Amengual J, Forner L. Reliability of two color selection devices in matching and measuring tooth color. J Contemp Dent Pract 2011;12:19-23.

19. Koo TK, Li MY. A guideline of selecting and reporting intraclass correlation coefficients for reliability research. J Chiropr Med 2016;15:155-63.

20. Lehmann KM, Igiel C, Schmidtmann I, Scheller H. Four color-measuring devices compared with a spectrophotometric reference system. J Dent 2010;38 Suppl 2:e65-70.

21. Yuan $\mathrm{K}$, Sun $\mathrm{X}$, Wang $\mathrm{F}$, Wang $\mathrm{H}$, Chen JH. In vitro and in vivo evaluations of three computer-aided shade matching instruments. Oper Dent 2012;37:219-27.

22. Hugo B, Witzel T, Klaiber B. Comparison of in vivo visual and computer-aided tooth shade determination. Clin Oral Investig 2005;9:244-50.

23. Lagouvardos PE, Fougia AG, Diamantopoulou SA, Polyzois GL. Repeatability and interdevice reliability of two portable color selection devices in matching and measuring tooth color. J Prosthet Dent 2009;101:40-5.

24.Karl Martin Lehmann, Alessandro Devigus, Christopher Igiel, Stefan Wentaschek, Mehdi Sattari Azar, Scheller H. Repeatability of colormeasuring devices. Eur J Esthet Dent 2011;6:42935.

Yazışma Adresi:

Tuba YILMAZ SAVAŞ

Selçuk Üniversitesi

Diş Hekimliği Fakültesi

Protetik Diş Tedavisi AD.

Konya, Türkiye

Tel : +90 3322231186

E Posta: tuba-yilmaz@windowslive.com 